\title{
Melatonin Reduces Inflammation and Cell Death in White Matter in the Mid-Gestation Fetal Sheep Following Umbilical Cord Occlusion
}

\author{
ANNE-KARIN WELIN, PERNILLA SVEDIN, RISTO LAPATTO, BO SULTAN, HENRIK HAGBERG, PIERRE GRESSENS, \\ INGEMAR KJELLMER, AND CARINA MALLARD
}

Department of Obstetrics and Gynecology [A.-K.W., B.S., H.H.], Department of Neuroscience and Physiology [P.S., C.M.], Department of Pediatrics [I.K.], Sahlgrenska Academy, Göteborg University, 40530 Göteborg, Sweden; Inserm, U676 [P.G.], Paris, FR-75019 France; Hospital for Children and Adolescents [R.L.], University of Helsinki, FIN-00029 Helsinki, Finland

\begin{abstract}
The premature infant is at increased risk of cerebral white matter injury. Melatonin is neuroprotective in adult models of focal cerebral ischemia and attenuates ibotenate-induced white matter cysts in neonatal mice. Clinically, melatonin has been used to treat sleep disorders in children without major side effects. The aim of this study was to investigate the protective and anti-inflammatory effects of melatonin in the immature brain following intrauterine asphyxia. Fetal sheep at $90 \mathrm{~d}$ of gestation were subjected to umbilical cord occlusion. Melatonin $(20 \mathrm{mg} / \mathrm{kg}, n=9)$ or vehicle $(n=10)$ was administered IV to the fetus, starting $10 \mathrm{~min}$ after the start of reperfusion and continued for $6 \mathrm{~h}$. Melatonin treatment resulted in a slower recovery of fetal blood pressure following umbilical cord occlusion, but without changes in fetal heart rate, acid base status or mortality. The production of 8-isoprostanes following umbilical cord occlusion was attenuated and there was a reduction in the number of activated microglia cells and TUNEL-positive cells in melatonin treated fetuses, suggesting a protective effect of melatonin. In conclusion, this study shows that melatonin attenuates cell death in the fetal brain in association with a reduced inflammatory response in the blood and the brain following intrauterine asphyxia in mid-gestation fetal sheep. (Pediatr Res 61: 153-158, 2007)
\end{abstract}

$\mathrm{T}$ The premature infant is at increased risk of cerebral white matter injury, often referred to as periventricular leukomalacia (PVL), which is associated with subsequent development of cerebral palsy and cognitive impairment $(1,2)$. The precise etiology of white matter damage remains unclear, but ischemia-reperfusion and generation of free radicals seem to play an important role (3). Presently, there are no effective treatments for preterm brain injury, although encouraging studies suggest that hypothermic treatment in term infants following birth asphyxia is successful in reducing mortality/ morbidity $(4,5)$.

Received July 5, 2006; accepted September 26, 2006

Correspondence: Professor Carina Mallard, Ph.D., Perinatal Center, Department of Neuroscience and Physiology, Sahlgrenska Academy, University of Göteborg, 40530 Göteborg, Sweden; e-mail: carina.mallard@fysiologi.gu.se

Supported by the Swedish Medical Research Council (K2004-33X-14185-03A), Åhlen Foundation, Sven Jerring Foundation, Magnus Bergvall Foundation, Wilhelm and Martina Lundgren Foundation, Linnéa and Josef Carlsson Foundation, Frimurare Barnhus Foundation, Göteborg Medical Society, Swedish governmental grants to scientists working in health care (ALFGBG-2863) and Åke Wibergs Foundation.

DOI: 10.1203/01.pdr.0000252546.20451.1a
Melatonin is the major secretory product of the pineal gland and its main physiologic function is to mediate circadian rhythmicity and seasonality (6). Clinically, melatonin has been used to treat sleep disorders in children and jet-lag $(7,8)$ and melatonin administered to neonates reduced oxidative stress in association with septicaemia (9). Furthermore, treatment with melatonin in asphyxiated newborns reduced levels of malondialdehyde and nitrite/nitrate in the blood (10).

In adult animals, melatonin has been shown to be neuroprotective in models of focal cerebral ischemia (11) and to reduce microglia activation in the hippocampus after kainateinduced inflammation in rats (12). Melatonin also attenuated ibotenate-induced white matter cysts in neonatal mice (13). In addition, melatonin given to pregnant rats prevented oxidative mitochondria damage after ischemia-reperfusion in premature fetal rat brain (14).

We have previously demonstrated white matter injury following systemic asphyxia in the preterm fetal sheep, which is similar to the injury seen in preterm infants (15). We found marked microglia activation and a prolonged increase in free radical production in association with white matter damage in the preterm fetal sheep brain following global asphyxia (16). The hypothesis of the present study was that administration of melatonin in a clinically relevant model of reperfusion injury in mid-gestational fetal sheep, reduces white matter injury and inflammation. Secondly, we wanted to investigate the fetal cardiovascular responses of fetal melatonin administration.

\section{MATERIALS AND METHODS}

Surgical procedure. Fifteen pregnant Gotland sheep ewes underwent aseptic surgery (Isofluran 1.5\%) at $89-90 \mathrm{GA}$ (term $=$ approximately $147 \mathrm{~d}$ ) as previously described (15). In brief, a vascular occluder (In Vivo Metric, OC16HD) was placed around the umbilical cord. Polyvinyl catheters were implanted in both axillary arteries of the fetus and in one of the axillary veins. One catheter was placed in the amnion and secured to the fetal skin. At the end of the surgery, a catheter was inserted in the saphenous vein of the ewe. In case of twins, both fetuses were instrumented.

Following surgery the ewes were kept in individual cages with free access to food and water. The animals were allowed to recover from surgery for two to four days before studies began. Antibiotics (Garamycin, $5 \mathrm{mg} / \mathrm{kg}$, IV) were administered to the ewe during the postoperative period.

Abbreviations: FHR, fetal heart rate; FMAP, fetal mean arterial blood pressure; PVL, periventricular leukomalacia 
Experimental procedures. At 91-93 GA fetuses were randomly allocated to two different groups; melatonin-treated $(n=9)$ or vehicle-treated $(n=10)$. In cases of twin pregnancies, both fetuses were given the same treatment. Asphyxia was induced by inflation of the umbilical vascular occluder for 23.5 min. This length of umbilical cord occlusion was chosen as pilot studies showed that it was the optimal duration to assure that brain damage was induced in all animals, but without causing fetal death.

Fetal blood samples $(1 \mathrm{~mL})$, were collected on ice preocclusion and at 20 min after the start of occlusion, and at 1, 6, 24 and $96 \mathrm{~h}$ after the end of the occlusion and immediately analyzed for blood gases $\left(\mathrm{pO}_{2}, \mathrm{pCO}_{2}, \mathrm{pH}\right.$, oxygen saturation $\left(\mathrm{SO}_{2}\right)$ and base deficit) and glucose and lactate (Radiometer ABL 725 , Copenhagen). Remaining blood was centrifuged and serum immediately frozen and stored at $-80 \mathrm{C}$ for later analysis (see below). Continuous blood pressure and heart rate was recorded on BIOPAC Systems (Goleta, CA), MPA 150. Melatonin (Sigma Chemical Co., (Sigma-Aldrich Swede AB, Stockholm, Sweden) dissolved in $10 \%$ ethanol in $0.9 \% \mathrm{NaCl}), 20 \mathrm{mg} / \mathrm{kg} / \mathrm{h}$ was administered IV $(1 \mathrm{~mL} / \mathrm{h})$ starting $10 \mathrm{~min}$ after the start of reperfusion and continued for $6 \mathrm{~h}$. The infusion line was covered with aluminium foil since melatonin is sensitive to light. Vehicle-treated fetuses were infused with $10 \%$ ethanol in $0.9 \% \mathrm{NaCl}$, using the same volume and rate as melatonin-treated animals. These studies were approved by the Animal Ethical Committee of the University of Göteborg.

Fetal mean arterial blood pressure and fetal heart rate measurement. Fetal mean arterial blood pressure (FMAP), fetal heart rate (FHR), and amniotic pressure were recorded on a computer (MP 150, Biopac Systems Inc.) at a sampling rate of $62.5 / \mathrm{s}$. Amniotic pressure was subtracted from FMAP to remove possible movement artifacts by the ewe. Mean FMAP and FHR were calculated during $15 \mathrm{~min}$ bins at $1 \mathrm{~h}$ before occlusion and at 1,2 , $3,4,5,6,8,10,12$ and $24 \mathrm{~h}$ after the occlusion. One measurement was also calculated during the last minute of occlusion.

8-Isoprostane analysis. Free 8-isoprostane concentration was measured in fetal serum samples with a commercial enzyme immunoassay kit (Cayman Chemical, Ann Arbor, MI). The samples were assayed in a 96-well plate coated with mouse anti-rabbit IgG MAb to 8-isoprostane. An 8-isoprostane tracer bound to acetylcholinesterase was used to compete for binding sites. Samples were analysed as $50 \mu \mathrm{L}$ aliquots and read at $420 \mathrm{~nm}$ in a microplate reader (Multiscan EX; Thermo Labsystems Oy, Vantaa, Finland). The range of standard curve was from 3.9 to $500 \mathrm{pg} / \mathrm{mL}$.

Thiol analysis Total and free thiol (cysteine, glutathione) levels in fetal serum were measured as previously described (17). In brief, free sulfhydryls of thiols were derivatized with monobromobimane to form fluorescent complexes. Thiols were then separated with HPLC (HPLC) and detected fluorometrically. This gives the concentration of free thiols. To measure the total (reduced + oxidized) concentration of glutathione or cysteine, aliquots of the samples were first treated with DTT to reduce disulphides.

Histology. Four days after the asphyxia, fetal brains were perfused in situ through the carotid arteries using saline $(0.9 \% \mathrm{NaCl})$ followed by $5 \%$ formaldehyde in phosphate buffer (Histofix, Histolab, Göteborg, Sweden), removed and weighed. Brains were postfixed in 5\% formaldehyde overnight, dehydrated in alcohol solutions and embedded in paraffin. Coronal sections $(8 \mu \mathrm{m})$ of the forebrain, including the cerebral cortex, underlying white matter, striatum, hippocampus and thalamus were cut on a microtome. Sections were stained with acid fuchsin and thionin (18) for morphologic analysis and adjacent sections were used for analysis as described below.

Microglia cells were detected using lectin histochemistry. Sections were boiled in citric acid buffer (0.01 M, pH 6.0) and incubated with $10 \mu \mathrm{g} / \mathrm{mL}$ Griffonia simplicifolia isolectin- $\mathrm{B}_{4}$-horseradish peroxidase conjugate (Sigma Chemical Co. L5391) overnight $\left(4^{\circ} \mathrm{C}\right)$ and visualized using 3,3diamionbenzidine (DAB).

Fragmented DNA was identified by the TUNEL technique. Sections were incubated with proteinase $\mathrm{K}, 15 \mu \mathrm{g} / \mathrm{mL}$ (15 min), $0.1 \mathrm{M}$ Tris- $\mathrm{HCl}, \mathrm{pH} 7.5$, containing $3 \%$ BSA (30 $\mathrm{min})$ and then incubated with TUNEL reaction mixture (Roche Diagnostics Scandinavia AB, Stockholm, Sweden) for $60 \mathrm{~min}$ at $37^{\circ} \mathrm{C}$. Sections were blocked for endogenous peroxidase $\left(0.3 \% \mathrm{H}_{2} \mathrm{O}_{2}\right.$ in methanol, $10 \mathrm{~min}$ ), incubated with $0.1 \mathrm{M}$ Tris- $\mathrm{HCl}, \mathrm{pH} 7.5$, containing $3 \%$ BSA (30 min) and incubated with TUNEL-POD for $30 \mathrm{~min}$ at $37^{\circ} \mathrm{C}$. Sections were visualized using DAB.

Neuropathological analysis. Analysis of the brains was performed by one observer unaware of the treatment of the animals. Images from acid fuchsin/ thionin stained sections, at the level of the anterior striatum, were captured (Olympus DP 50) at $1 \times$ magnification and saved on a PC. The left lateral ventricle and the left hemisphere were outlined and the area calculated (Micro Image Version 4.0, Olympus, Tokyo, Japan).

An overall damage score was used to evaluate gross neuropathological changes in evenly spaced acid fuchsin/thionin and lectin stained sections from the forebrain: $0=$ no morphologic alterations; $1=$ few activated microglia and/or small areas of diffuse white matter necrosis and/or $<10 \%$ of neuronal injury in striatum, thalamus and/or cortex; 2 = moderate number of activated microglia cells, several smaller areas of diffuse white matter necrosis and/or $>10 \%$ of neuronal injury in striatum, thalamus and/or cortex; $3=$ significant number of activated microglia, large area of diffuse white matter necrosis or focal cystic formation and/or $>50 \%$ of neuronal injury in striatum, thalamus and/or cortex.

Activation of microglia cells was determined by two methods. Microglia cells were counted using a $40 \times$ objective at the level of the anterior striatum and hippocampus, in three white matter areas on each section; the external capsule, the periventricular white matter above the lateral ventricle and the subcortical white matter in parietal cortex. Each image was captured by a camera (Olympus DP50) and corresponded to $0.0768 \mathrm{~mm}^{2}$. The mean number of cells per white matter region was calculated.

The density and distribution of microglia cells were analyzed using a $1 \times$ objective at the levels of the anterior striatum and hippocampus. Images were captured using a camera (Olympus DP50) and saved to a computer and then processed (Micro Image Version 4.0, Olympus, Tokyo, Japan) using the segmentation tool. Using this processing tool, the grey level of the microglia staining was visually identified and isolated from the background, resulting in a black and white image with the microglia staining being black and the background white. In these images the area of the white matter was outlined and the sum of black pixels was determined within the outlined area, which represented the density and distribution of microglia staining within the white matter.

Sections stained with TUNEL were analyzed in five regions: the parietal cortex, dorsal thalamus, white matter of the external capsule, the periventricular white matter and the subcortical white matter underlying the parietal cortex. All regions were at the level of the anterior hippocampus. Computer images of the above regions were collected using the $40 \times$ objective. The color images were converted into gray images and then segmented into black and white images as described above. This allowed isolation of darkly stained TUNEL-positive cells from the background. The number of cells (stained particles of $<30 \mu \mathrm{m}^{2}$ were not included in the analysis) were counted in the segmentation processed images using image analysis software (Micro Image Version 4.0, Olympus, Tokyo, Japan).

Statistics. Sample size $(n=10)$ was calculated with power set at 0.7 , population mean difference at 30 and SD at 25 (alpha $=0.05)$. Animals in the melatonin treatment group were compared with the vehicle group, with respect to blood gas measurement, FMAP and FHR by repeated measure ANOVA. In cases of missing values, the mean value of the prior and subsequent value was used, except during asphyxia when the mean value of the group was chosen. In cases of an overall difference the Bonferroni correction for multiple comparisons was used. Histologic results were compared using Mann Whitney's test. Statistical analyses were performed using GraphPad Prism 4. All data are presented as mean \pm SD.

\section{RESULTS}

Blood gases. Umbilical cord occlusion resulted in severe reductions in oxygenation and $\mathrm{pH}$ in association with an increased $\mathrm{pCO}_{2}$ and base deficit (Table 1). Except for the metabolic acidosis, most parameters were normalized by $1 \mathrm{~h}$ after reperfusion and there were no differences between melatonin and vehicle treated groups, except for $\mathrm{SO}_{2}$ measurement in the melatonin treated group, which was still somewhat lower $1 \mathrm{~h}$ post occlusion (Table 1 ).

FMAP and FHR. During the umbilical cord occlusion an initial rise in arterial blood pressure occurred followed by a gradual drop in all animals. There was no difference in FMAP at the end of occlusion in vehicle treated $(16.3 \pm 2.2 \mathrm{~mm} \mathrm{Hg}$, $n=6)$ and melatonin treated $(14.9 \pm 1.5 \mathrm{~mm} \mathrm{Hg}, n=7)$ fetuses $(p>0.05)$. FMAP recovered by $3 \mathrm{~h}$ after umbilical cord occlusion in vehicle treated animals, while FMAP had normalized by $8 \mathrm{~h}$ in melatonin treated animals (Fig. 1). There was also a group $(p=0.0293)$ and interaction $(p=0.0209)$ effect between melatonin treated and vehicle treated animals.

FHR immediately fell in all animals and remained low during the umbilical cord occlusion (Fig. 1). Following reperfusion, all animals demonstrated normal FHR at $1 \mathrm{~h}$ postoc- 
Table 1. Arterial blood gases, lactate and glucose measurements following umbilical cord occlusion

\begin{tabular}{|c|c|c|c|c|c|c|c|}
\hline & \multirow[b]{2}{*}{ Treatment } & \multirow[b]{2}{*}{ Pre-1h } & \multirow[b]{2}{*}{ Occlusion $22 \mathrm{~min}$} & \multicolumn{4}{|c|}{ Recovery } \\
\hline & & & & $1 \mathrm{~h}$ & $6 \mathrm{~h}$ & $24 \mathrm{~h}$ & $96 \mathrm{~h}$ \\
\hline $\begin{array}{l}\mathrm{pO}_{2} \\
\quad(\mathrm{kPa})\end{array}$ & $\begin{array}{l}\text { Vehicle } \\
\text { Melatonin }\end{array}$ & $\begin{array}{l}3.4 \pm 0.3 \\
3.5 \pm 0.3\end{array}$ & $\begin{array}{l}1.0 \pm 0.8+++ \\
1.3 \pm 1.1 * * *\end{array}$ & $\begin{array}{l}3.3 \pm 0.3 \\
3.1 \pm 0.2\end{array}$ & $\begin{array}{l}3.4 \pm 0.4 \\
3.3 \pm 0.3\end{array}$ & $\begin{array}{l}3.5 \pm 0.3 \\
3.5 \pm 0.2\end{array}$ & $\begin{array}{l}3.6 \pm 0.4 \\
3.6 \pm 0.6\end{array}$ \\
\hline $\begin{array}{l}\mathrm{pCO}_{2} \\
\quad(\mathrm{kPa})\end{array}$ & $\begin{array}{l}\text { Vehicle } \\
\text { Melatonin }\end{array}$ & $\begin{array}{l}5.8 \pm 0.4 \\
6.0 \pm 0.4\end{array}$ & $\begin{array}{l}15.9 \pm 2.1+++ \\
15.2 \pm 2.2 * * *\end{array}$ & $\begin{array}{l}5.9 \pm 0.3 \\
6.2 \pm 0.3\end{array}$ & $\begin{array}{l}6.0 \pm 0.5 \\
6.0 \pm 0.4\end{array}$ & $\begin{array}{l}6.1 \pm 0.3 \\
6.3 \pm 0.3\end{array}$ & $\begin{array}{l}6.0 \pm 0.1 \\
6.3 \pm 0.4\end{array}$ \\
\hline $\begin{array}{l}\mathrm{SO}_{2} \\
\quad(\%)\end{array}$ & $\begin{array}{l}\text { Vehicle } \\
\text { Melatonin }\end{array}$ & $\begin{array}{l}68.7 \pm 6.5 \\
68.2 \pm 3.3\end{array}$ & $\begin{array}{l}6.1 \pm 5.0+++ \\
7.0 \pm 4.6^{* * *}\end{array}$ & $\begin{array}{l}64.9 \pm 7.2 \\
57.0 \pm 5.5 * * *\end{array}$ & $\begin{array}{l}68.0 \pm 9.9 \\
63.2 \pm 7.2\end{array}$ & $\begin{array}{l}70.2 \pm 5.0 \\
70.1 \pm 3.4\end{array}$ & $\begin{array}{l}69.0 \pm 3.5 \\
69.6 \pm 4.0\end{array}$ \\
\hline $\mathrm{pH}$ & $\begin{array}{l}\text { Vehicle } \\
\text { Melatonin }\end{array}$ & $\begin{array}{l}7.37 \pm 0.01 \\
7.34 \pm 0.02\end{array}$ & $\begin{array}{l}6.82 \pm 0.04+++ \\
6.80 \pm 0.02 * * *\end{array}$ & $\begin{array}{l}7.33 \pm 0.02+++ \\
7.30 \pm 0.03^{*} * *\end{array}$ & $\begin{array}{l}7.37 \pm 0.02 \\
7.35 \pm 0.02\end{array}$ & $\begin{array}{l}7.37 \pm 0.01 \\
7.36 \pm 0.02 *\end{array}$ & $\begin{array}{l}7.37 \pm 0.01 \\
7.34 \pm 0.04\end{array}$ \\
\hline $\begin{array}{l}\mathrm{BE} \\
(\mathrm{mmol} / \mathrm{l})\end{array}$ & $\begin{array}{l}\text { Vehicle } \\
\text { Melatonin }\end{array}$ & $\begin{array}{l}-0.3 \pm 1.6 \\
-0.9 \pm 2.1\end{array}$ & $\begin{array}{l}-15.0 \pm 2.0+++ \\
-15.7 \pm 2.2 * * *\end{array}$ & $\begin{array}{l}-2.8 \pm 1.7++ \\
-3.2 \pm 2.1^{*}\end{array}$ & $\begin{array}{r}0.0 \pm 2.2 \\
-0.4 \pm 2.0\end{array}$ & $\begin{array}{l}1.2 \pm 1.0 \\
1.0 \pm 1.1 * *\end{array}$ & $\begin{array}{l}0.6 \pm 0.9 \\
0.1 \pm 2.9\end{array}$ \\
\hline $\begin{array}{l}\text { Glucose } \\
\qquad(\mathrm{mmol} / \mathrm{l})\end{array}$ & $\begin{array}{l}\text { Vehicle } \\
\text { Melatonin }\end{array}$ & $\begin{array}{l}1.1 \pm 0.2 \\
1.2 \pm 0.3\end{array}$ & $\begin{array}{l}0.4 \pm 0.2+++ \\
0.4 \pm 0.1 * * *\end{array}$ & $\begin{array}{l}1.4 \pm 0.2++ \\
1.4 \pm 0.3^{*}\end{array}$ & $\begin{array}{l}1.4 \pm 0.3++ \\
1.4 \pm 0.3^{*}\end{array}$ & $\begin{array}{l}1.1 \pm 0.3 \\
1.3 \pm 0.2\end{array}$ & $\begin{array}{l}1.1 \pm 0.3 \\
1.3 \pm 0.2\end{array}$ \\
\hline $\begin{array}{l}\text { Lactate } \\
\qquad(\mathrm{mmol} / \mathrm{l})\end{array}$ & $\begin{array}{l}\text { Vehicle } \\
\text { Melatonin }\end{array}$ & $\begin{array}{l}1.0 \pm 0.1 \\
1.1 \pm 0.2\end{array}$ & $\begin{array}{l}8.6 \pm 1.2+++ \\
7.7 \pm 1.2 * * *\end{array}$ & $\begin{array}{l}3.2 \pm 0.5+++ \\
3.3 \pm 0.6^{* * *}\end{array}$ & $\begin{array}{l}1.2 \pm 0.2 \\
1.2 \pm 0.4\end{array}$ & $\begin{array}{l}1.0 \pm 0.1 \\
1.0 \pm 0.2\end{array}$ & $\begin{array}{l}1.2 \pm 0.2 \\
1.0 \pm 0.2\end{array}$ \\
\hline
\end{tabular}

Repeated measure ANOVA, vehicle $n=8$; melatonin $n=8$.

$+++p<0.001$ vs. Veh pre; $++p<0.01$ vs. Veh pre.

*** $p<0.001$ vs. Mel pre; ** $p<0.01$ vs. Mel pre; $* p<0.05$ vs. Mel pre.

clusion and there were no differences in FHR between the melatonin treated and the vehicle treated group before, during or after asphyxia ( $p=0.1599)$.

8-isoprostanes and thiols in blood serum. Two-way ANOVA analysis revealed a significant effect on 8-isoprostane concentrations with time $(p<0.001)$, demonstrating an increase in vehicle treated animals at $6 \mathrm{~h}$ after reperfusion, while there was no significant rise in melatonin treated fetuses (Fig. $2 A)$. There was no group $(p=0.2196)$ or interaction $(p=0.1674)$ effects between melatonin and vehicle treated animals. There were no significant changes in cystein (Fig. $2 B$ ) or glutathione (Fig. $2 C$ ) concentrations in either vehicle

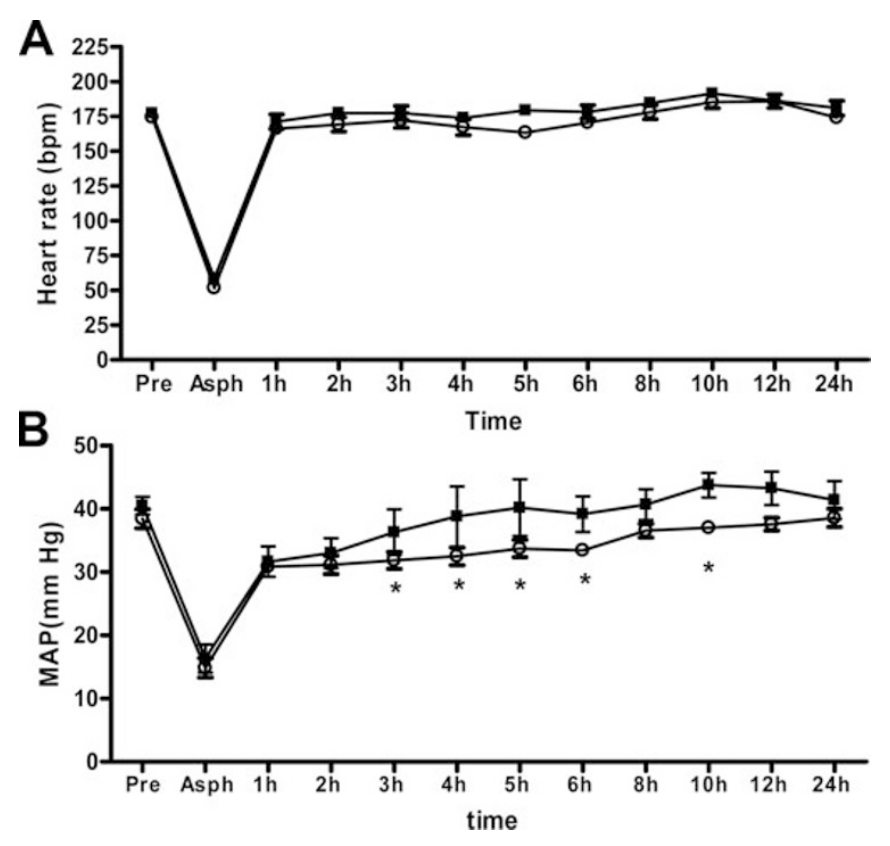

Figure 1. Fetal mean arterial pressure $(A)$ and fetal heart rate $(B)$ in vehicle (ם) and melatonin $(O)$ treated animals following umbilical cord occlusion. Repeated measure ANOVA with Bonferroni correction, ${ }^{*} p<0.05$ melatonin vs. control. treated compared with pre-insult or melatonin treated compared with vehicle treated animals.

Brain injury. There were no differences in gross neuropathological score between vehicle $(2.1 \pm 0.9, n=10)$ and melatonin $(1.6 \pm 0.9, n=8)$ treated animals $(p>0.05$, Fig. $3 A)$. The area of the right hemisphere and the size of the ventricles were also similar in the two groups (Fig. 3B, C). The number of TUNEL-positive cells was reduced in the subcortical white matter and also in the thalamus in melatonintreated fetuses compared with vehicle treated animals (Fig. $3 D-F)$.

There was a significant decrease in the number of activated microglia cells in the melatonin treated group compared with the vehicle group in the periventricular white matter and the subcortical white matter at the level of the striatum and in the external capsule and periventricular white matter at the level of the hippocampus (Fig. 4A-E). Furthermore, the density and distribution measurement of microglia staining, was reduced in the melatonin-treated group compared with the vehicle group at the level of striatum (Fig. 4F).

\section{DISCUSSION}

In this study we have shown that postasphyxial melatonin treatment attenuated the increase in activated microglia and 8 -isoprostane production and at the same time reduced the number of TUNEL-positive cells in the cerebral white matter in midgestation fetal sheep. The 6-h IV melatonin infusion was associated with a slower recovery of fetal arterial pressure following umbilical cord occlusion but did not affect mortality.

We found that there were fewer TUNEL-positive cells in the white matter in the melatonin treated animals, suggesting a reduction in cell death. As these cells were not characterized we can only speculate on their origin, but we have previously shown that both astrocytes and oligodendrocytes are injured after prolonged asphyxia (15). Several studies have shown neuroprotective effects of melatonin in adult animal models of 

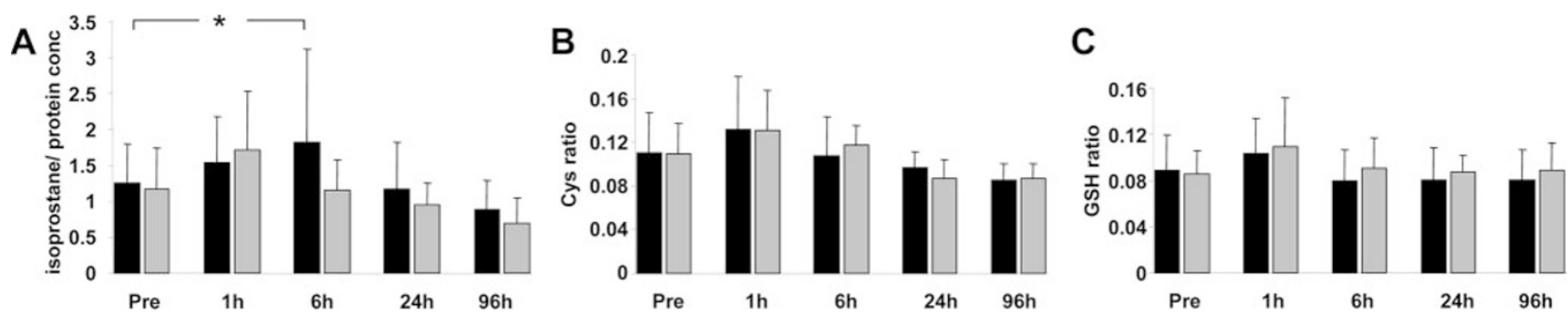

Figure 2. Serum measurements of 8 -isoprostane (A), Cysteine (Cys) ratio $(B)$ and glutathione (GSH) ratio $(C)$ before (pre-) and after (1, 6, 24 and $96 \mathrm{~h}$ ) umbilical cord occlusion in fetal sheep. Vehicle (black bars, $n=9$ ) and melatonin (grey bars, $n=10$ ) treated animals. Repeated measure ANOVA, ${ }^{*} p<0.05 v s$. pre-insult.

ischemic stroke (11). In these studies melatonin given at doses of more than $5 \mathrm{mg} / \mathrm{kg}$, with treatment starting either before or during ischemia, showed maximum protection. In contrast, experiments in term fetal sheep did not find an effect of melatonin treatment on DNA/RNA fragmentation following umbilical cord occlusion, although the increase in hydroxyl radicals was prevented (19). However, these experiments differed from the present study with regard to several aspects; a lower melatonin dose $(1 \mathrm{mg} / \mathrm{kg})$ and shorter infusion period (2h) were used and the drug was administered to the mother rather than the fetus. Neonatal mice, where melatonin was given at significantly lower doses $(0.0005-5.0 \mathrm{mg} / \mathrm{kg})$, showed a dose-dependent reduction of periventricular white
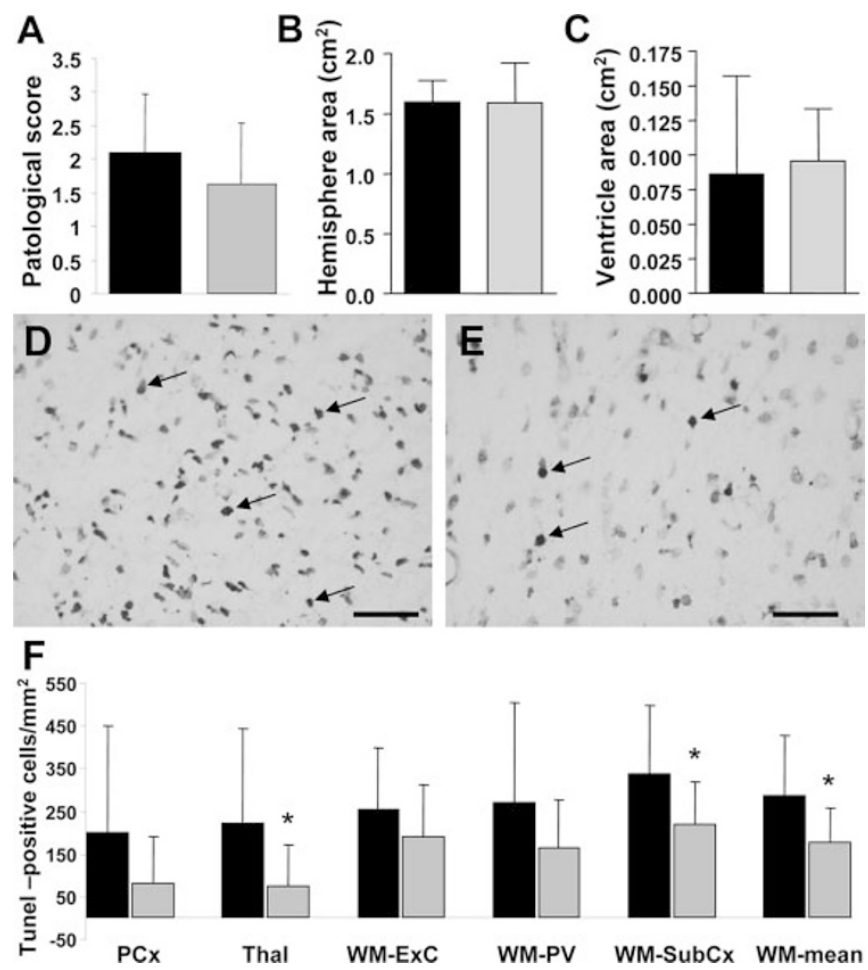

Figure 3. Pathologic score $(A)$, size of the left hemisphere $(B)$ and lateral ventricle $(C)$ and number of TUNEL-positive cells $/ \mathrm{mm}^{2}(F)$ in vehicle (black bars, $n=9$ ) and melatonin (grey bars, $n=10$ ) treated animals following umbilical cord occlusion. Examples of TUNEL-positive cells (arrows) in sub-cortical white matter in vehicle $(D)$ and melatonin-treated fetuses $(E)$. Scale bar in D \& E $=150 \mu \mathrm{m}$. PCx, parietal cortex; Thal, thalamus; WM-ExC, external capsule in the white matter; WM-PV, periventricular white matter; WM-SubCx, Subcortical white matter; WM-mean, average number of cells in the three white matter regions. Mann-Whitney test, $* p<$ 0.05 vs. vehicle treated. matter damage after ibotenate-induced injury and this protection was suppressed by co-administration of luzindole, a melatonin receptor antagonist, suggesting a receptor-mediated protection (13). The dosage of melatonin is likely to affect the mechanisms involved in the brain protection and the higher dose used in the present study has probably targeted oxidative stress, and might even have desensitized the melatonin receptors.

Melatonin has been suggested to act as an immunomodulator by preventing the translocation of nuclear factor-kappa $\mathrm{B}$ $(\mathrm{NF}-\kappa \mathrm{B})$ to the nucleus, thereby reducing the up-regulation of pro-inflammatory cytokines (20). In support of this melatonin was shown to reduce kainate-induced neuronal death and microglia activation in the hippocampus in adult rats (12) and we have observed that melatonin ameliorates cerebral infarction in an animal model of bacterial endotoxin-induced hypoxic-ischemic brain injury in neonatal rats (Wang et al., unpublished observation). Furthermore, when given to newborn mice, melatonin delayed the initial increase of microglia activation after ibotenate-induced white matter damage, suggesting anti-inflammatory properties of melatonin (13). Similarly, in our study the number and distribution of activated microglia cells were reduced in the cerebral white matter.

Our observation of an attenuation of microglia activation fours days after asphyxia in melatonin treated animals does not necessarily mean a decrease in brain injury in the longterm. However, excessive activation of microglia and the consequent production of pro-inflammatory cytokines are believed to be neurotoxic and microglia activation has been demonstrated in association with experimental studies of neonatal brain damage (21-23). An increase in the expression of TNF- $\alpha$ was also found in brain autopsies from infants with PVL and these cytokines were mainly expressed by microglia cells and hypertrophic astrocytes (24). We have previously shown that microglia are activated following hypoxiaischemia in the neonatal rat, which is associated with an increased expression of pro-inflammatory cytokines such as IL- $1 \beta$ and IL-18. Furthermore, the deletion of the IL-18 gene, but not IL- $1 \beta$, conferred protection of both the grey and white matter indicating the importance of excessive production of cytokines in the immature brain (25-27).

Excessive stimulation of microglia can contribute to oxidative damage by production of injurious reactive species (28). Evidence of oxidative stress and lipid peroxidation in premyelinating oligodendrocytes has been shown in autopsy brains from premature children with PVL, suggesting that these are 

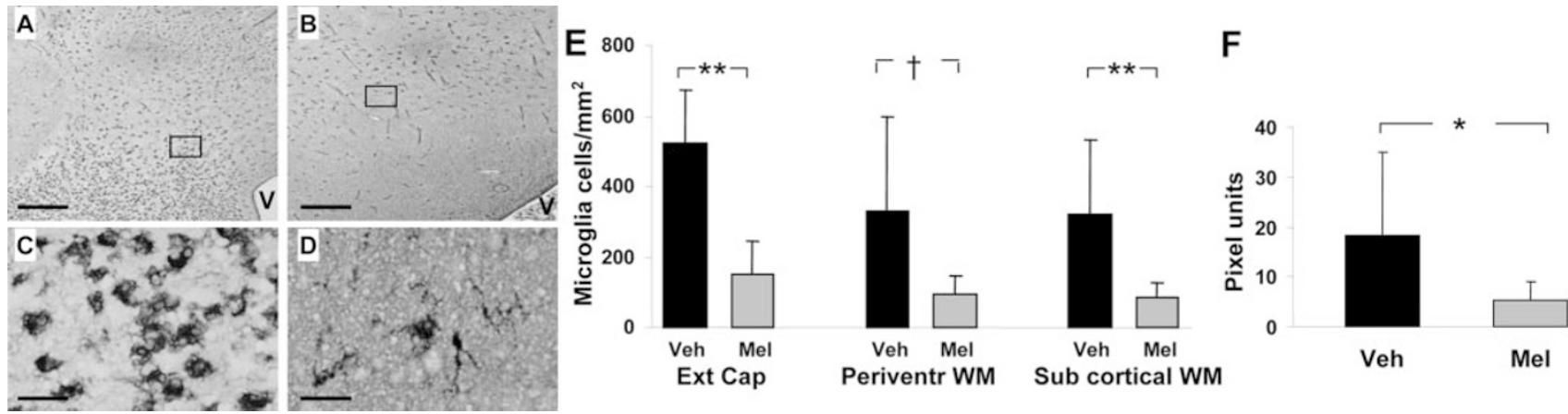

Figure 4. Microglia cell analysis. Photomicrographs of examples of lectin-positive cells (microglia) in the periventricular white matter in vehicle $(A, C)$ and melatonin- $(B, D)$ treated fetuses. The boxes in $A$ and $B$ are shown at higher magnification in $C$ and $D$, respectively. Scale bars in $A$ and $B=0.75 \mathrm{~mm}$; and in $C$ and $D=40 \mu \mathrm{m}$. Microglia counts $(E)$ and distribution of microglia activation $(F)$ in vehicle (black bars, $n=9)$ and melatonin (grey bars, $n=10)$ treated animals following umbilical cord occlusion. V, lateral ventricle. White matter regions: ExtC, external capsule; Periventr WM, periventricular white matter; Subcortical WM, subcortical white matter. Mann-Whitney test, $\dagger p<0.001 v s$. vehicle treated; $* * p<0.01 v s$. vehicle treated; $* p<0.05 v s$. vehicle treated.

important factors in white matter injury (29). An increase in free radical products in the cerebrospinal fluid in premature infants with white matter damage has also been demonstrated (30). We have previously demonstrated a long-lasting increase in free radical production in the cerebral white matter following intrauterine asphyxia in the mid-gestation fetal sheep (16). In the present study we found an increase in lipid peroxidation, as shown by 8 -isoprostanes in the blood, following umbilical cord occlusion and melatonin limited this increase. Although, these results do not show a direct effect on lipid peroxidation in the brain, the findings are in agreement with clinical studies showing a correlation between increased 8-isoprostane in plasma and later development of PVL (31).

In the present study, melatonin was administered at a relatively high dose, $20 \mathrm{mg} / \mathrm{kg} / \mathrm{h}$, for $6 \mathrm{~h}$ and although there was no overall difference in fetal arterial blood pressure between vehicle and melatonin treated animals, the recovery was slower and fetal arterial blood pressure was reduced compared with pre-insult values for $6 \mathrm{~h}$ after asphyxia in melatonin treated fetuses. Melatonin has been shown to reduce blood pressure in men with uncomplicated, untreated hypertension (32) and when given to normotensive, young men (33). The underlying mechanism is unknown, however melatonin is thought to activate receptors in vascular smooth muscle and the activation of melatonin receptor 2 may cause relaxation (34). However, despite the effect on blood pressure, there were no adverse effects on fetal heart rate, fetal survival or blood gas status following melatonin treatment. Similarly, pregnant rats given high doses of melatonin $(200 \mathrm{mg} / \mathrm{kg} / \mathrm{d}$ for $15 \mathrm{~d}$ ) showed no significant effects on prenatal survival, fetal body weight or malformations (35). In patients with Parkinson's disease, no apparent side effects have been seen at doses near 100 $\mathrm{mg} / \mathrm{kg} / \mathrm{d}$ (36). In addition, melatonin has been given to neurologically disabled children at doses between 2 and $12 \mathrm{mg}$ to improve their sleep pattern (8), without any major side effects.

In conclusion, this study shows that a single dose of melatonin attenuates the increase in activated microglia, and TUNEL-positive cells in the cerebral white matter and isoprostane production in the blood following intrauterine asphyxia in mid-gestation fetal sheep. This is the first study to suggest a protective effect of melatonin on fetal white matter injury. Importantly, melatonin was shown to reduce inflam- mation and cell death when administered after the insult and showed no major adverse cardiovascular effects.

\section{REFERENCES}

1. Banker BQ, Larroche JC 1962 Periventricular leukomalacia of infancy. A form of neonatal anoxic encephalopathy. Arch Neurol 7:386-410

2. Perlman JM 1998 White matter injury in the preterm infant: an important determination of abnormal neurodevelopment outcome. Early Hum Dev 53:99-120

3. Volpe JJ 2001 Neurobiology of periventricular leukomalacia in the premature infant Pediatr Res 50:553-562

4. Gluckman PD, Wyatt JS, Azzopardi D, Ballard R, Edwards AD, Ferriero DM, Polin RA, Robertson CM, Thoresen M, Whitelaw A, Gunn AJ 2005 Selective head cooling with mild systemic hypothermia after neonatal encephalopathy: multicentre randomised trial. Lancet 365:663-670

5. Shankaran S, Laptook AR, Ehrenkranz RA, Tyson JE, McDonald SA, Donovan EF, Fanaroff AA, Poole WK, Wright LL, Higgins RD, Finer NN, Carlo WA, Duara S, Oh W, Cotten CM, Stevenson DK, Stoll BJ, Lemons JA, Guillet R, Jobe AH 2005 Whole-body hypothermia for neonates with hypoxic-ischemic encephalopathy. N Engl J Med 353:1574-1584

6. Claustrat B, Brun J, Chazot G 2005 The basic physiology and pathophysiology of melatonin. Sleep Med Rev 9:11-24

7. Herxheimer A, Petrie KJ 2002 Melatonin for the prevention and treatment of jet lag. Cochrane Database Syst Rev 2:CD001520

8. Jan MM 2000 Melatonin for the treatment of handicapped children with severe sleep disorders. Pediatr Neurol 23:229-232

9. Gitto E, Karbownik M, Reiter RJ, Tan DX, Cuzzocrea S, Chiurazzi P, Cordaro S, Corona G, Trimarchi G, Barberi I 2001 Effects of melatonin treatment in septic newborns. Pediatr Res 50:756-760

10. Fulia F, Gitto E, Cuzzocrea S, Reiter RJ, Dugo L, Gitto P, Barberi S, Cordaro S, Barberi I 2001 Increased levels of malondialdehyde and nitrite/nitrate in the blood of asphyxiated newborns: reduction by melatonin. J Pineal Res 31:343-349

11. Macleod MR, O'Collins T, Horky LL, Howells DW, Donnan GA 2005 Systematic review and meta-analysis of the efficacy of melatonin in experimental stroke. J Pineal Res 38:35-41

12. Chung SY, Han SH 2003 Melatonin attenuates kainic acid-induced hippocampal neurodegeneration and oxidative stress through microglial inhibition. J Pineal Res 34:95-102

13. Husson I, Mesples B, Bac P, Vamecq J, Evrard P, Gressens P 2002 Melatoninergic neuroprotection of the murine periventricular white matter against neonatal excitotoxic challenge. Ann Neurol 51:82-92

14. Watanabe K, Wakatsuki A, Shinohara K, Ikenoue N, Yokota K, Fukaya T 2004 Maternally administered melatonin protects against ischemia and reperfusioninduced oxidative mitochondrial damage in premature fetal rat brain. J Pineal Res 37:276-280

15. Mallard C, Welin AK, Peebles D, Hagberg H, Kjellmer I 2003 White matter injury following systemic endotoxemia or asphyxia in the fetal sheep. Neurochem Res 28:215-223

16. Welin AK, Sandberg M, Lindblom A, Arvidsson P, Nilsson UA, Kjellmer I, Mallard C 2005 White matter injury following prolonged free radical formation in the 0.65 gestation fetal sheep brain. Pediatr Res 58:100-105

17. Ahola T, Fellman V, Laaksonen R, Laitila J, Lapatto R, Neuvonen PJ, Raivio KO 1999 Pharmacokinetics of intravenous $\mathrm{N}$-acetylcysteine in pre-term new-born infants. Eur J Clin Pharmacol 55:645-650

18. Mallard EC, Williams CE, Gunn AJ, Gunning MI, Gluckman PD 1993 Frequent episodes of brief ischemia sensitize the fetal sheep brain to neuronal loss and induce striatal injury. Pediatr Res 33:61-65

19. Miller SL, Yan EB, Castillo-Melendez M, Jenkin G, Walker DW 2005 Melatonin provides neuroprotection in the late-gestation fetal sheep brain in response to umbilical cord occlusion. Dev Neurosci 27:200-210 
20. Reiter RJ, Calvo JR, Karbownik M, Qi W, Tan DX 2000 Melatonin and its relation to the immune system and inflammation. Ann N Y Acad Sci 917:376-386

21. McRae A, Gilland E, Bona E, Hagberg H 1995 Microglia activation after neonatal hypoxic-ischemia. Brain Res Dev Brain Res 84:245-252

22. Mesples B, Plaisant F, Fontaine RH, Gressens P 2005 Pathophysiology of neonatal brain lesions: lessons from animal models of excitotoxicity. Acta Paediatr 94:185190

23. Hedtjarn M, Mallard C, Hagberg H 2004 Inflammatory gene profiling in the developing mouse brain after hypoxia-ischemia. J Cereb Blood Flow Metab 24:1333-1351

24. Yoon BH, Romero R, Kim CJ, Koo JN, Choe G, Syn HC, Chi JG 1997 High expression of tumor necrosis factor-alpha and interleukin-6 in periventricular leukomalacia. Am J Obstet Gynecol 177:406-411

25. Hedtjarn M, Leverin AL, Eriksson K, Blomgren K, Mallard C, Hagberg H 2002 Interleukin-18 involvement in hypoxic-ischemic brain injury. J Neurosci 22:5910 5919

26. Hedtjarn M, Mallard C, Iwakura Y, Hagberg H 2005 Combined deficiency of IL-1beta18, but not IL-1alphabeta, reduces susceptibility to hypoxia-ischemia in the immature brain. Dev Neurosci 27:143-148

27. Hedtjarn M, Mallard C, Arvidsson P, Hagberg H 2005 White matter injury in the immature brain: role of interleukin-18. Neurosci Lett 373:16-20

28. Dringen R 2005 Oxidative and antioxidative potential of brain microglial cells. Antioxid Redox Signal 7:1223-1233
29. Haynes RL, Folkerth RD, Keefe RJ, Sung I, Swzeda LI, Rosenberg PA, Volpe JJ, Kinney HC 2003 Nitrosative and oxidative injury to premyelinating oligodendrocytes in periventricular leukomalacia. J Neuropathol Exp Neurol 62:441-450

30. Inder T, Mocatta T, Darlow B, Spencer C, Volpe JJ, Winterbourn C 2002 Elevated free radical products in the cerebrospinal fluid of VLBW infants with cerebral white matter injury. Pediatr Res 52:213-218

31. Ahola T, Fellman V, Kjellmer I, Raivio KO, Lapatto R 2004 Plasma 8-isoprostane is increased in preterm infants who develop bronchopulmonary dysplasia or periventricular leukomalacia. Pediatr Res 56:88-93

32. Scheer FA, Van Montfrans GA, van Someren EJ, Mairuhu G, Buijs RM 2004 Daily nighttime melatonin reduces blood pressure in male patients with essential hypertension. Hypertension 43:192-197

33. Lusardi P, Preti P, Savino S, Piazza E, Zoppi A, Fogari R 1997 Effect of bedtime melatonin ingestion on blood pressure of normotensive subjects. Blood Press Monit 2:99-103

34. Doolen S, Krause DN, Dubocovich ML, Duckles SP 1998 Melatonin mediates two distinct responses in vascular smooth muscle. Eur J Pharmacol 345:67-69

35. Jahnke G, Marr M, Myers C, Wilson R, Travlos G, Price C 1999 Maternal and developmental toxicity evaluation of melatonin administered orally to pregnant Sprague-Dawley rats. Toxicol Sci 50:271-279

36. Papavasiliou PS, Cotzias GC, Duby SE, Steck AJ, Bell M, Lawrence WH 1972 Melatonin and parkinsonism. JAMA 221:88-89 